\title{
Recurrence of Giant Cell Tumor of Posterior Tibialis Tendon
}

\author{
${ }^{1}$ Karan R Choudhry, ${ }^{2}$ Vishal N Mandlewala
}

\section{ABSTRACT}

Aim: To present a case of recurrence of giant cell tumor of the tendon sheath (GCT TS) and its management.

Background: The GCT TS is a solitary benign soft tissue tumor of the limbs. It usually appears as an enlarging painless mass and has a synovial origin. The GCT TS is approximately $1.6 \%$ of all soft tissue tumors. The GCT TS of tibialis posterior is very rare, and recurrence has not been reported.

Case report: A 21-year-old male patient presents with complaint of swelling over right ankle since 3 years. Patient was operated for swelling 10 years back, and histological examination revealed GCT TS. Patient was asymptomatic for 3 years after operation and then developed swelling since last 3 years. On local examination, hypertrophic scar mark $1 \times 4 \mathrm{~cm}$ was present at right medial malleolus. Ultrasonography of right medial malleolus and magnetic resonance imaging were done for further evaluation. Under spinal anesthesia and tourniquet control, medial approach was taken extending from $7 \mathrm{~cm}$ above the medial malleolus posterior to the tibia up to the talar head. Tissue was cleared and was sent for histopathology, which confirmed the diagnosis of GCT TS. Patient is on regular follow-up since then, and there has not been any recurrence.

Conclusion: Though rare, recurrence of GCT TS can occur, and it should be properly investigated and completely excised.

Clinical significance: Though recurrence of GCT TS is rarely reported, it needs to be dealt with a high index of suspicion and treated aggressively.

Keywords: Excision, Giant cell tumor, Recurrence, Tibialis posterior tendon sheath.

How to cite this article: Choudhry KR, Mandlewala VN. Recurrence of Giant Cell Tumor of Posterior Tibialis Tendon. J Foot Ankle Surg (Asia-Pacific) 2017;4(1):45-48.

\section{Source of support: Nil}

Conflict of interest: None

\section{INTRODUCTION}

Giant cell tumor of the tendon sheath (nodular tenosynovitis, localized villonodular synovitis, fibrous

\footnotetext{
${ }^{1}$ Associate Surgeon, ${ }^{2}$ Assistant Surgeon

1,2Department of Orthopedics, Asutosh Multi Speciallty Hospital Surat, Gujarat, India
}

Corresponding Author: Karan R Choudhry, Associate Surgeon, Department of Orthopedics, Asutosh Multi Speciallty Hospital, Surat, Gujarat, India, e-mail: vishalmandlewala@ gmail.com histiocytoma of the synovium; GCT TS) is a solitary benign soft tissue tumor of the limbs. ${ }^{1-3}$ It usually appears as an enlarging painless mass and has a synovial origin. ${ }^{4}$ The GCT TS is approximately $1.6 \%$ of all soft tissue tumors. An overall incidence is 1 in 50,000 individuals is seen, and usually affects people between 30 and 50 years; it is more often seen in women. Female-to-male ratio is $3: 210 .^{5}$ The most frequent tumor is in the hand (exceeded in that location only by ganglion cyst), especially the fingers - the index finger $(29.7 \%)$ followed by the thumb $(12.9 \%)$, the long $(24.6 \%)$, the ring $(16.8 \%)$, and then the little $(16 \%)$ fingers. ${ }^{6}$ Giant cell tumor of tibialis posterior is very rare and recurrence has not been reported. Tumor usually surrounds a nearby tendon or more rarely the neurovascular bundles.

\section{CASE REPORT}

A 21-year-old male patient with complaint of swelling over right ankle since 3 years was involved. Patient was asymptomatic 10 years back when he had history of trauma on his medial side of ankle. Pain was acute in onset and progressive in nature with severe intensity associated with swelling in right ankle. Histopathology reporting was done during his first surgery, which revealed giant cell tumor of tibialis posterior tendon. He was operated for swelling over right ankle 6 years ago. He was asymptomatic for 3 years after operation, and then developed swelling the last year. On local examination, hypertrophic scar mark $1 \times 4 \mathrm{~cm}$ was present at right medial malleolus. Swelling, at present, was $2 \times 3 \mathrm{~cm}$ in size, which was reducible, mobile, and nontender. Patient did not have any other swelling elsewhere in the body. Plain X-ray of ankle anteroposterior and lateral was done (Figs 1A and B), and ultrasound of the local part gave a differential diagnoses as chronic granulomatous tenosynovitis and giant cell tumor of tendon. Magnetic resonance imaging was done for confirmation (Figs 2A and B). Under spinal anesthesia and tourniquet control, medial approach was taken extending from $7 \mathrm{~cm}$ above the medial malleolus posterior to the tibia upto the talar head. Soft tissue dissection was done. A bunch of grape-like pale yellow mass were seen, which were originating from the ankle joint and was involving the tibialis posterior tendon. A thorough debulking was done and the tendon was freed. Neurovascular structures were inspected and were free 


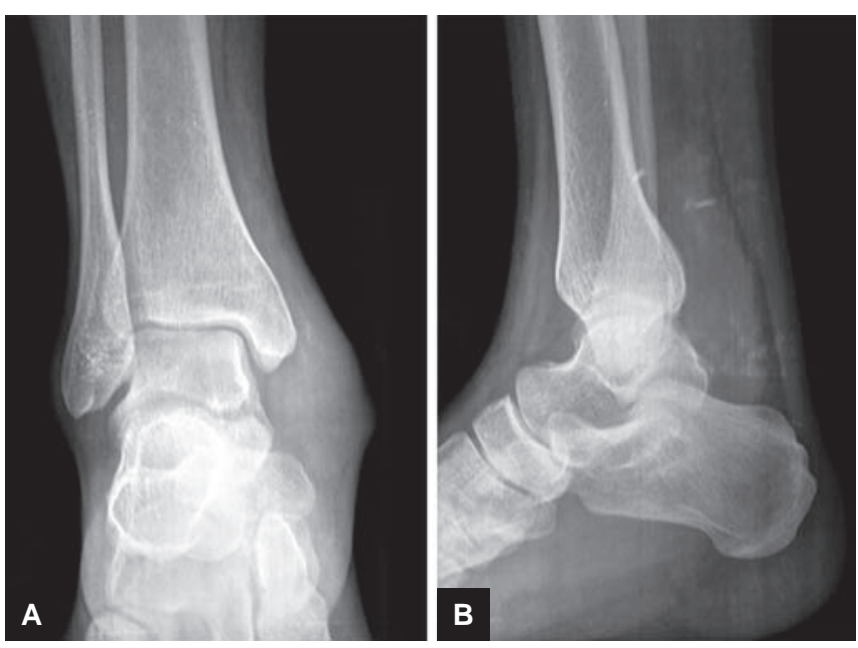

Figs 1 A and B: X-ray: (A) Anteroposterior; and (B) lateral view of the ankle

from any involvement. The extent of the masses was up to $7 \mathrm{~cm}$ above the calcaneum proximally and up to the navicular distally, which was cleared. Thorough wash was given. Ankle mobility was checked and wound was closed. The tissue was sent for histopathology, which confirmed the diagnosis of GCT TS (Figs 3A, B and 4). Stitches were removed on 12th day and healed without any complication. Patient is on regular follow-up since then, and there has not been any recurrence.

\section{DISCUSSION}

The GCT TS is a benign tumor of uncertain pathogenesis. It was first described in the international literature by Jaffe et al in 1941. ${ }^{7}$ The GCT TS is also known as the localized form of the pigmented villonodular synovitis (PVNS). Both entities have the same histologic features, and they are classified as "fibrohistiocytic tumors" in the World Health Organization (WHO) classification system for bone and soft tissue tumors of 2013. The WHO nomenclature describes the tumor as GCT TS for pigmented villonodular tenosynovitis or pigmented villonodular bursitis, diffuse variety of giant cell tumor for the diffuse intra-articular form of PVNS. ${ }^{8}$ The localized form can arise in or extrinsic to a joint, and the diffuse form predominantly originates outside the joint. The GCT TS appears as a rubbery, multinodular, well-encapsulated, brown, orange, or yellow mass; the color depends on the proportion of foam cells and degree of hemosiderin deposition. Collagenous capsule surrounds the lesion. Patients may report a history of trauma to the affected area, for which there is a debate on whether the tumor is a true neoplasm or a pseudoneoplastic inflammatory response to soft tissue trauma. The tumor usually surrounds a nearby tendon or more rarely the neurovascular bundles. It is thought that tumor arises from synovial cell of tendon sheath, joint, or bursa. The GCT TS grows outward from tendon sheath, whereas PVNS grows inward from synovial lining into joint. ${ }^{7}$ According to some authors, the typical site is volar aspect of hand and finger, most commonly at the metatarsophalangeal joint. Dorsal location is rare. Feet are the second most common site and seen in 3 to $10 \%$ - most commonly, fore foot, especially the great toe. Less common sites include

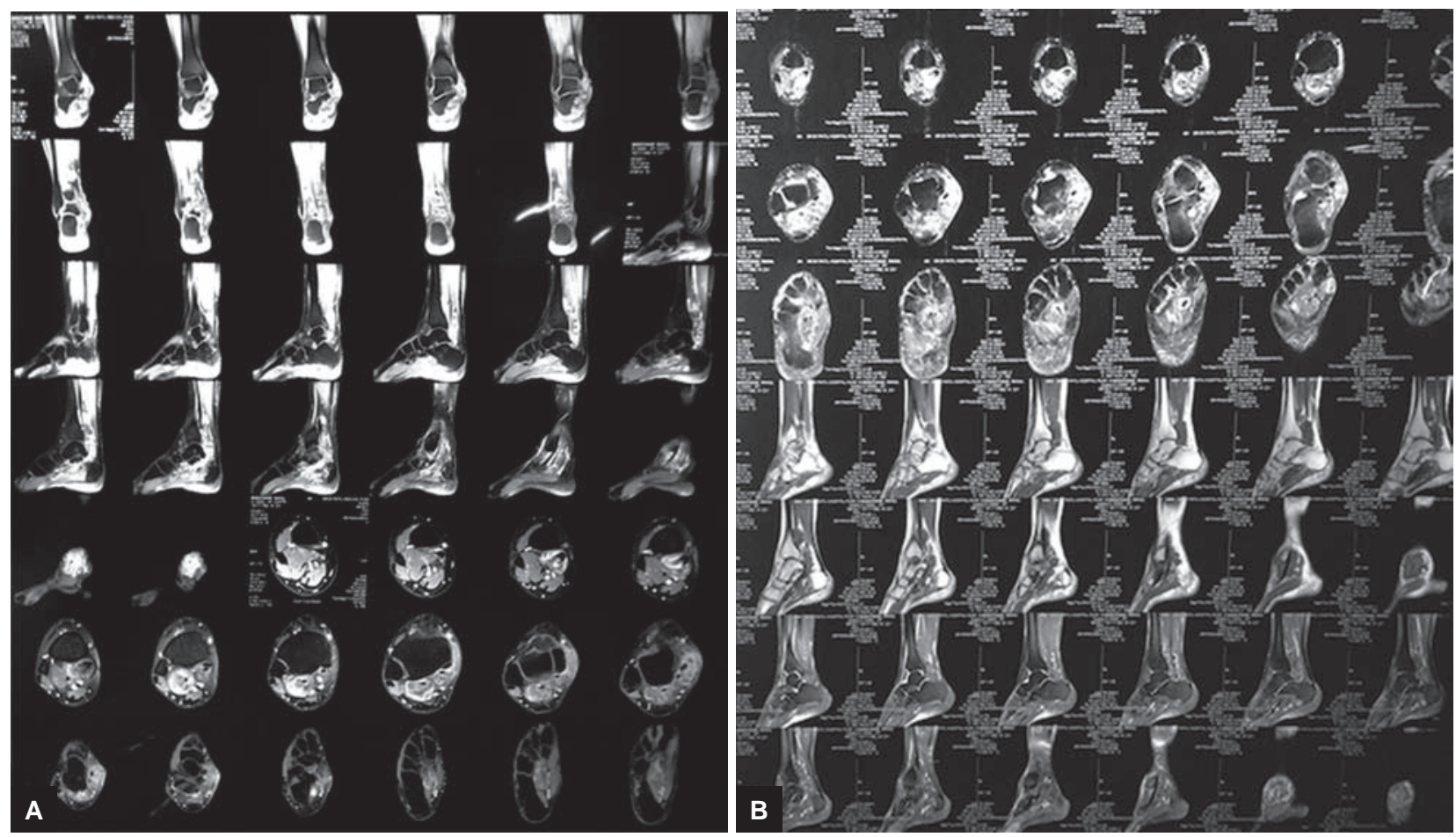

Figs 2A and B: Magnetic resonance imaging of the ankle: (A) Coronal, sagittal; and (B) axial sections demonstrating the recurrence pathology 

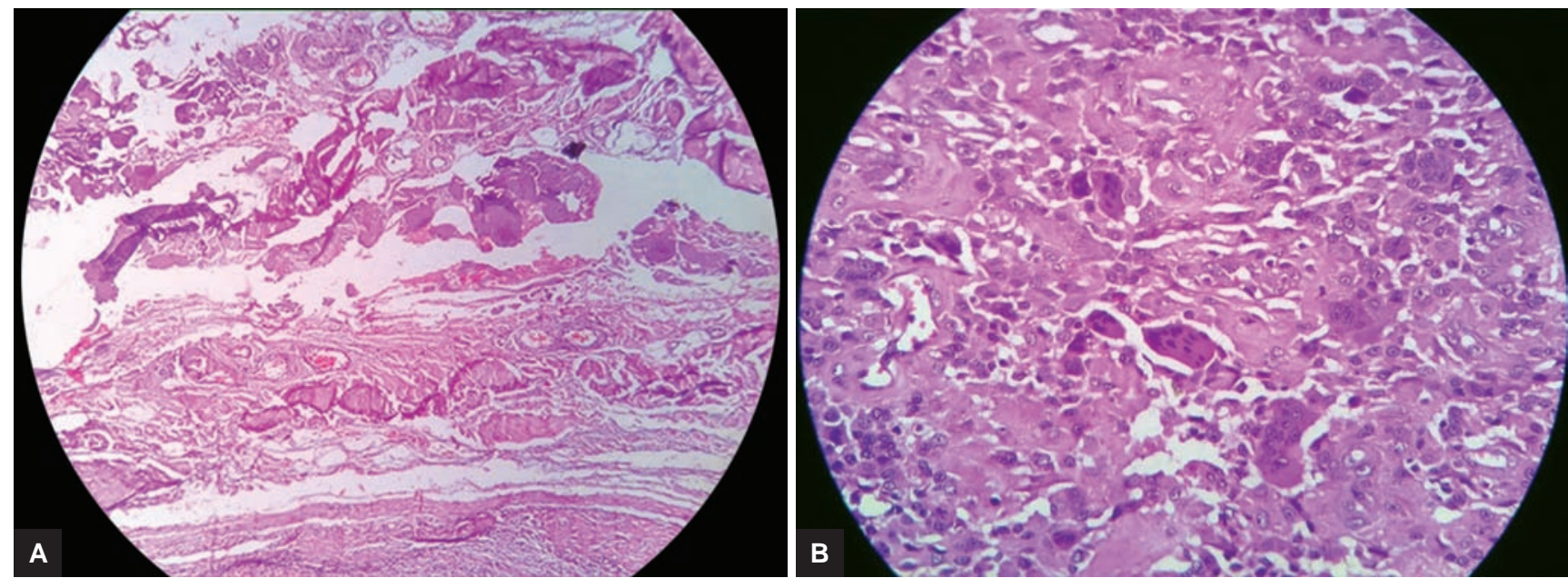

Figs 3A and B: Histopathology slides under microscope demonstrating tumor recurrence

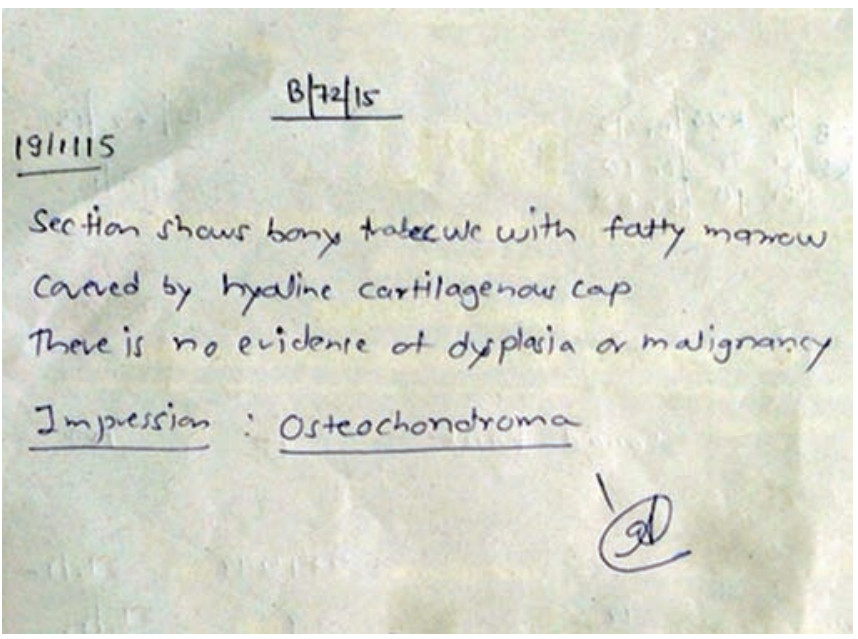

Fig. 4: Histopathological reporting of the tissue

extra-articular areas around the large joints, such as knee, wrist, ankle, and spine. ${ }^{9}$ The GCT TS is histologically similar to PVNS. Both lesions are characterized by the deposition of hemosiderin, and there are usually numerous macrophages, including foamy macrophages and scattered macrophage polykaryons. The pathogenesis is uncertain. They are mostly small in size (average tumor size, $2.0 \mathrm{~cm}$ ), albeit lesions of greater size may be found in the large joints. They are usually well-circumscribed and typically lobulated. ${ }^{10}$ Due to pressure effects, this tumor can cause erosions. They have been observed in 9 to $25 \%$ of cases, and they usually manifest as small cortical defects. Neurological symptoms are not a common feature of GCT TS. So, if there is pain or neurogenic symptoms with a solitary lesion of the limb, a nerve sheath tumor or soft tissue sarcoma should be suspected in the differential diagnosis. ${ }^{11}$ Tumors are superficial lesions usually located within the first centimeter of the field-of-view; the first method to diagnose GCT TS could be ultrasound due to its high resolution for small structures, such as tendons and ligaments. It can detect whether tumor is solid or cystic, and provide information about the tumor vascularity, size, and its relation to the surrounding tissue. Close contact with the tendon sheath or joint does make this tumor a primary consideration when diagnosing soft tissue mass near a tendon sheath or a joint. ${ }^{12}$ In the differential diagnosis, we should think about giant cell tumor of soft tissue and giant cell tumor of bone. These tumors may be differentiated by the presence of necrosis, metaplastic bone formation, and aneurysmal bone cystlike areas, and their typical location is at the back, thigh, and shoulder. ${ }^{13,14}$ Differential diagnosis also includes ganglion cyst, a desmoid tumor lipoma, malignant fibrous histiocytoma, synovial sarcoma, and other soft tissue tumors. Ganglion cysts can be differentiated from GCT by ultrasound. Aneuploid cells have been noted by deoxy ribonucleic acid flow cytometry in a significant number of cases. ${ }^{10}$ Grover et al, ${ }^{15}$ in a study of 52 cases of GCT TS of the hand investigated the expression of nm23 using immune histochemical techniques on paraffin sections. Absence of this gene in $21 \%$ of these tumors was found to correlate strongly with a statistically significant risk of local recurrence. Clonal abnormalities, including a translocation involving chromosomes 1,2, and 16, have also been noted in GCT TS. ${ }^{3,16,17}$ Patient has been on follow-up for 1 year; no recurrence has been noted. We are presenting this case as it is a rare site, and recurrence has not been reported.

\section{CONCLUSION}

Though rarely reported of recurrence of GCT TS, it needs to be dealt with high index of suspicion and treated aggressively.

\section{REFERENCES}

1. Jones FE, Soule EH, Coventry MB. Fibrous xanthoma of synovium (giant celltumour of tendon sheath, pigmented nodular synovitis). A study of one hundred and eighteen cases. J Bone Joint Surg Am 1969 Jan;51(1):76-86. 
2. Ushijima $M$, Hashimoto $H$, Tsuneyoshi $M$, Enjoji $M$, Miyamoto Y, Okue A. Malignant giant cell tumor of tendon sheath. Report of a case. Acta Pathol Jpn 1985 May;35(3):699-709.

3. Weiss, SW.; Goldblum, JR. Benign tumors and tumor-like lesions of synovial tissues. In: Enzinger and Weiss's soft tissue tumors. Mosby; 2001. p. 1037-1062.

4. Eisenstein R, Giant-cell tumor of tendon sheath. Its histogenesis as studied in the electron microscope. J Bone Joint Surg Am 1968 Apr;50(3):476-485.

5. Monaghan H, Salter DM, Al-Nafussi A. Giant cell tumour of tendon sheath (localized nodulartenosynovitis) clinicopathological features of 71 cases. J Clin Pathol 2001 May; 54(5):404-407.

6. Di Grazia S, Succi G, Fragetta F, Perrotta RE. Giant cell tumor of tendon sheath: study of 64 cases and review of literature. G Chir 2013 May-Jun;34(5-6):149-152.

7. Jaffe HL, Lichtenstein L, Sutro CJ. Pigmented villonodularsynovitis, bursitis and tenosynovitis. Arch Pathol 1941 Jun;31(3):731-765.

8. Somerhausen, NS.; Cin, P. Giant cell tumours of tendon sheath-diffuse type of HCT. In: Pathology and genetics of tumours of soft tissue and bone. Lyon: IARC; 2002. p. 110-114.

9. Dingle SR, Flynn JC, Flynn JC Jr, Stewart G. Giant-cell tumour of the tendon sheath involving the cervical spine. A case report. J Bone Joint Surg Am 2002 Sep;84-A(9):1664-1667.
10. Sun C, Sheng W, Yu H, Han J. Giant cell tumor of the tendon sheath: a rare case in the left knee of a 15 -year-old boy. Oncol Lett 2012 Mar;3(3):718-720.

11. Gibbons CL, Khwaja HA, Cole AS, Cooke PH, Athanasou NA. Giant-cell tumour of the tendon sheath in the foot and ankle. J Bone Joint Surg Br 2002 Sep;84(7):1000-1003.

12. Darwish FM, Haddad WH. Giant cell tumour of tendon sheath: experience with 52 cases. Singapore Med J 2008 Nov;49(11):879-882.

13. Oliveira AM, Dei Tos AP, Fletcher CD, Nascimento AG. Primary giant cell tumor of soft tissues: a study of 22 cases. Am J Surg Pathol 2000 Feb;24(2):248-256.

14. O'Connell JX, Wehrli BM, Nielsen GP, Rosenberg AE. Giant cell tumors of soft tissue: a clinicopathologic study of 18 benign and malignant tumors. Am J Surg Pathol 2000 Mar;24(3):386-395.

15. Grover R, Grobbelaar AO, Richman PT, Smith PJ. Measurement of invasive potential provides an accurate prognostic marker for giant cell tumour of tendon sheath. J Hand Surg 1998;23B:728-731.

16. Dal Cin P, Scoit R, De Smet L, Van Damme B, Van Den Berghe $\mathrm{H}$. A new cytogenetic subgroup intenosynovial giant cell tumors (nodular tenosynovitis) is characterized by involvement of 16q24. Cancer Genet Cytogenet 1996 Mar;87(1):85-87.

17. Reilly KE, Stern PJ, Dale JA. Recurrent giant cell tumors of the tendon sheath. J Hand Surg Am 1999 Nov;24(6):1298-1302. 